\title{
CHRONIC TUBERCULOUS HILUS PNEUMONIA IN CHILDREN *
}

DAVID GREENBERG, M.D.

Assistant in Pathology and Admitting Physician, Lebanon Hospital NEW YORK

No disease has received more attention in the literature than tuberculosis, especially pulmonary tuberculosis, yet the subject is by no means exhausted. There is a type of pulmonary tuberculosis infrequently met with in children which is often overlooked, unless constantly kept in mind.

The most frequent form of tuberculosis in children, aside from tuberculous meningitis and miliary tuberculosis, is tuberculous pneumonia, either of the lobar pneumonic or bronchopneumonic type. Chronic tuberculosis as met with in adults is almost unknown in infants and children under 2 years of age. With the aid of the roentgen ray more cases of the chronic and subacute forms are being discovered. (Reuben, ${ }^{1}$ Dunn, ${ }^{2}$ Eisler,${ }^{3}$ and Wesler and Bass, ${ }^{4}$ speak of such cases.)

The type of tuberculosis to which I wish to call attention may be defined as a diffuse or parenchymatous process involving that portion of the lung immediately adjacent to the hilus. It is characterized by a gradual onset, comparatively mild constitutional symptoms, fairly definite physical signs (except early), and, as a rule, ends in recovery.

The mode of entry, as in most other forms of pulmonary tuberculosis, is probably through the respiratory tract, according to the views of Hamburger, ${ }^{5}$ Ghon ${ }^{6}$ and Dunn ${ }^{2}$ in this country. This point is by no means definitely settled.

The pathology is not definitely known. There are no necropsy reports and we only know the roentgen-ray and clinical findings, as determined by physical examination. Early roentgenologic studies reveal considerable enlargement of the tracheobronchial glands. This

* Received for publication, Aug. 15, 1920.

1. Reuben, M. S.: Fever, Initial Sign in Tuberculosis of Children, Arch. Pediat. 33:171, 1916. 1916.

2. Dunn, C. H.: Tuberculosis in Infancy, Am. J. Dis. Child. 11:85 (Feb.)

3. Eisler, F.: Die Interlobare Pleuritische Schwarte der Kindischen Lunge im Roentgenbilde, München. med. Wchnschr. No. 35, 1899 (Aug.) 1912.

4. Wessler, H., and Bass, M. H.: Recurrent Hilus Infection in Children, Am. J. Dis. Child. 11:198 (March) 1916.

5. Hamburger, F.: Die Tuberculose des Kindesalters, Leipzig u. Wien., 1912.

6. Ghon, A.: Der Primäre Lungenherd bei der Tuberculose der Kinder, Berlin u. Wien., 1912. 
would speak for a direct extension from the glands into adjacent lung tissue. The process usually assumes a more or less triangular outline, with the base toward the hilus, according to Wesler and Bass, who have studied these cases roentgenologically. The apex has a tendency to follow the interlobar fissure. The lesion is more common on the right side, and the shadow is irregular both as to outline and density in different parts of the lung. There is no great tendency toward cavity formation or calcification. When healing occurs there may be very little evidence of fibrosis or scar formation, either as determined by physical signs or the roentgen-ray examination.

The clinical history is not uniform. The earliest manifestations are irregular fever (Fig. 1), occurring in a child otherwise well, and stationary or slight loss in weight. The early fever in tuberculous children was emphasized by Reuben. ${ }^{1}$ It may occur at an early age. One of my patients became ill when 12 months old. Sluka's ${ }^{7}$ statement that chronic tuberculosis of this type does not occur under two years does not seem to be without exception. The fever is at first moderate, from 101 to $102 \mathrm{~F}$., and may either be remittent or intermittent. With the fever there is increase in pulse rate, fretfulness and considerable sweating. As the disease progresses, the fever becomes higher, from 103 to $104 \mathrm{~F}$., the pulse becomes more rapid and there may be some gastro-intestinal disturbances, especially in infants when the fever is high. Profuse perspiration is an early and frequent accompaniment of the fever and usually occurs in the early morning hours (Fischberg ${ }^{8}$ ).

Cough occurs sooner or later. It may be very slight in the early stages and is often overlooked, but it becomes more manifest later. Dyspnea may be mentioned as an early symptom, especially on exertion, as when the child is examined. The child then breathes as if there were some expiratory obstruction, reminding one of the neighing of a horse and somewhat resembling asthmatic breathing.

The physical signs, too, are variable. Early they may be absent or so slight as not to be detected. The first sign in one of my cases was diminished breathing. Frazer ${ }^{9}$ gives dulness as the earliest sign of tuberculosis in children. As the disease progresses the dulness and diminished breathing become more marked and distant bronchial breathing also may appear. Râles are often present, especially along

7. Sluka, E.: Die Hilus Tuberculose des Kindes im Roentgenbilde, Wien. klin. Wchnschr., (Feb.) 1912, p. 259; ibid., (Feb.) 1913, p. 254.

8. Fishberg, M.: Pulmonary Tuberculosis, Ed. 2, Philadelphia, Lea \& Febiger, 1919; Diagnosis of Pulmonary Tuberculosis in Children of School Age, Med. Rec. 92:406 (Sept. 18) 1917.

9. Frazier, K.: Early Tuberculosis in Children, Brit. J. Tuberc. 9:1, 1915. 


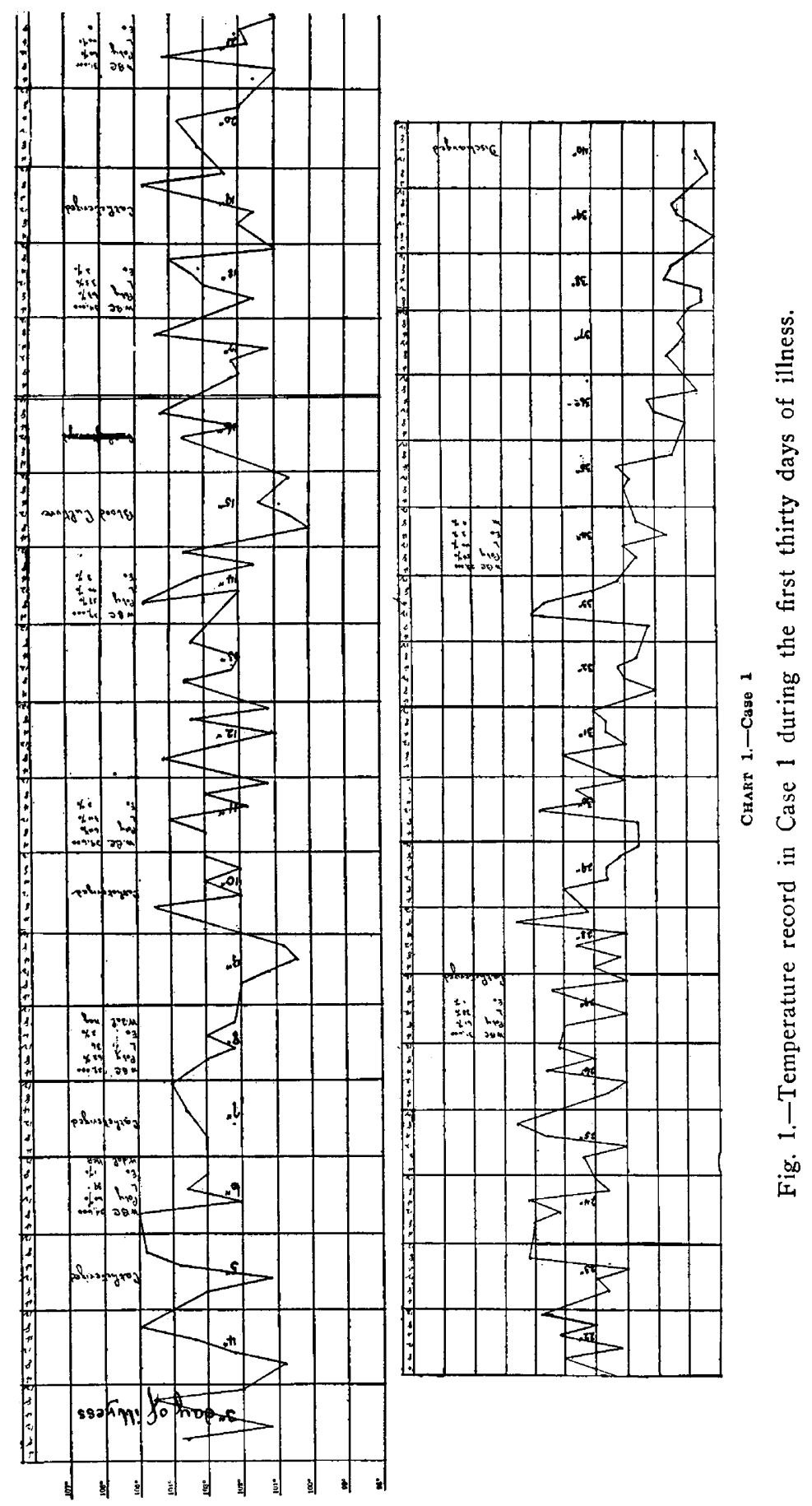


the margins of the process, when it is extending. Late there usually are râles over the entire lesion. These signs may extend and become so definite that the presence of fluid or large pulmonary abscess is diagnosed. Increased respiration, limitation of expansion, increased fremitus and retraction may also occur. The liver and spleen were enlarged in one of my cases and there were palpable glands in the supraclavicular fossa.

The course of the disease is toward recovery. It may, however, last for many months or even years.

There may be a leukocytosis. There are not many reports as to the blood picture in the literature. My own observations seem to indicate that a high white blood count is not incompatible with tuberculosis in infants and children. In one of the cases here reported the white blood count was persistently high, ranging from 24,000 to 34,000 per c.mm., with a polymorphonuclear percentage of from 64 to 71 . The urine may show a trace of albumin, even in the absence of other evidence of renal involvement. There is no particular tendency toward anemia. The sputum is scanty and it requires persistent effort and painstaking examination in order to demonstrate tubercle bacilli. In one of my cases it was only after the twentieth examination that I was able to demonstrate tubercle bacilli in the sputum. Injection of the sputum into a guinea-pig may demonstrate tubercle bacilli earlier. The roentgen-ray findings were discussed under pathology.

The diagnosis may be made more often if Hamberger's " dictum, "think of tuberculosis when no other diagnosis can be made," and the possibility of this kind of tuberculosis, is kept in mind. Given a child with prolonged irregular fever, even without definite lung signs, tuberculosis should be suspected. When in addition to the fever there is dulness and diminished breathing and only an occasional cough, or dyspnea, tuberculosis must be considered until ruled out. The following diagnostic points are relied on: (1) Von Pirquet; (2) sputum examination; (3) roentgen-ray examination; (4) lung puncture, and (5) enlarged supraclavicular glands.

Von Pirquet: The von Pirquet is of more value than it is generally believed to be. Frazer ${ }^{10}$ regards it as of distinct value even up to the tenth year. Veeder and Johnson ${ }^{11}$ are of the same opinion. It certainly is of great value up to 2 years of age.

Sputum Examination: The presence of tubercle bacilli found either by direct examination or on guinea-pig inoculation, makes the diagnosis.

10. Frazer, T.: The Significance of the von Pirquet, Med. Rec. 87:57, 1915.

11. Veeder, B. S., and Johnson, M. R.: The Frequency of Infection with the Tubercle Bacillus in Childhood, Am. J. Dis. Child. 9:478 (June) 1915. 
Roentgen-Ray Examination: A characteristic triangular shadow is to be considered presumptive evidence of this form of tuberculosis.

Lung Puncture: The method of puncture recommended is to use a fairly large needle with a little sterile water in the needle or syringe. Introduce the needle in several directions and aspirate. When it is withdrawn empty the contents of the needle into a sterile test tube. The material thus withdrawn is divided into sever 1 portions and examined for the presence of tubercle bacilli by direct spread, for giant cells, and some of it is injected into a guinea-pig.

Enlarged Supraclavicular Glands: Enlarged glands just above the clavicle on the side of the lesion is another point strongly suggestive of active tuberculosis.

This type of tuberculosis has to be differentiated from the following diseases: unresolved pneumonia, either with or without bronchiectasis, pulmonary abscess and encysted empyema, tracheobronchial adenitis, foreign body in the lung, actinomycosis, neoplasm of the lung and streptothrix infections.

The prognosis of tuberculosis (pulmonary) in children is rather serious. The younger the patient the graver the outlook, yet in this type of tuberculosis, as in tracheobronchial adenitis, the prog nosis is favorable. The patients whose cases I am reporting recovered, at least clinically. The patients of Wesler and Bass, ${ }^{4}$ which evidently belong to the group, also recovered. Increase in weight, steady diminution in temperature and decrease or entire disappearance of cough, are among the early favorable signs.

The treatment is not different from that generally advised for other forms of pulmonary tuberculosis. It consists in the dietetic and hygienic régime. A change of climate is advisable if circumstances allow it. The child should reside in the country, preferably at a considerable altitude, for a year or more. The open air and heliotherapy recommended by Freeman ${ }^{12}$ for other pulmonary conditions is of great value here also. Sleeping outdoors is comparatively simple for a child if an intelligent mother or nurse is in attendance. The diet should be liberal, but great care must be exercised against overfeeding, especially in the younger patients.

\section{REPORT OF CASES}

Case 1.-(This case was published incompletely in a previous communication. $^{13}$ ) B. B., female, 1 year old.

Family History.-Negative.

Previous History.-Normal birth, breast-fed up to 7 months, mixed feeding up to the tenth month, weaned at 10 months. Put on formula of top milk. Did well up to present illness.

12. Freeman, R. G.: Fresh Air in Pediatric Practice, Am. J. Dis. Child. 12: 590 (Dec.) 1916.

13. Med. Rec. 97:736, 1920 . 


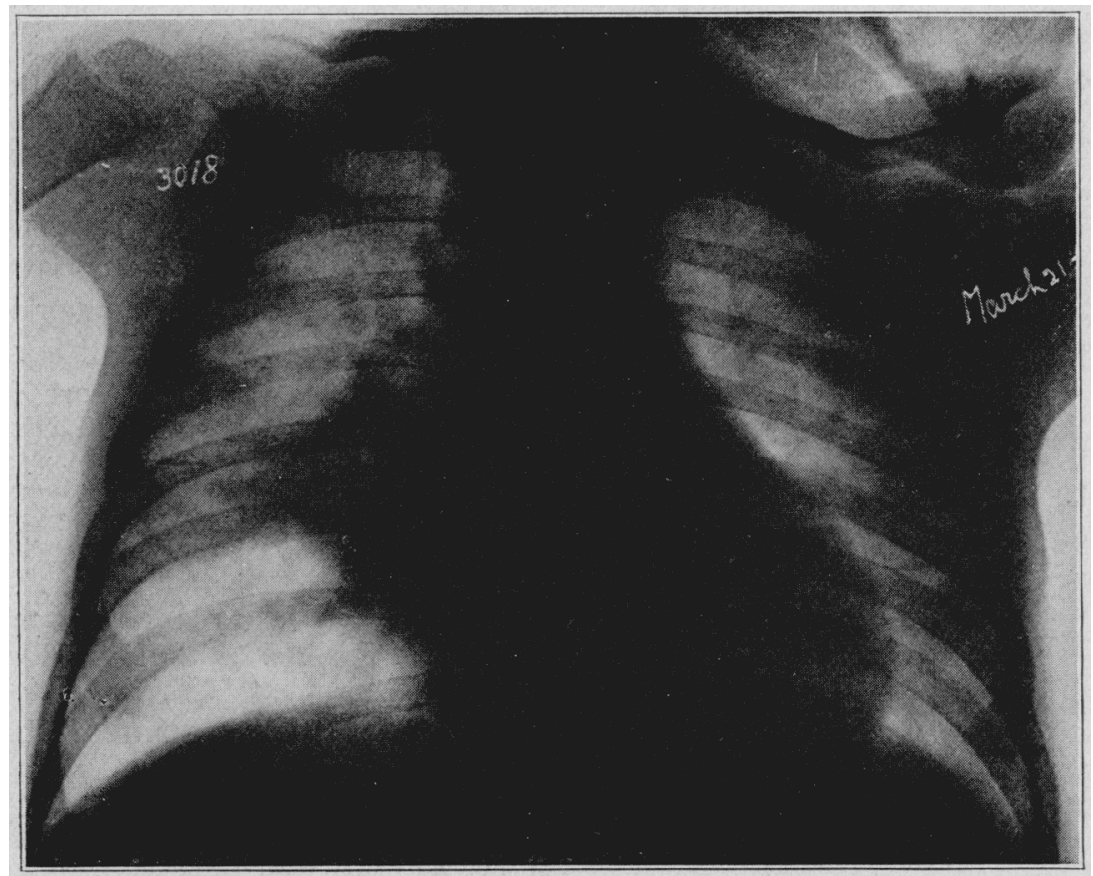

Fig. 2.- Case 1. Triangular hilus infiltration with the apex extending along the intertian fissure

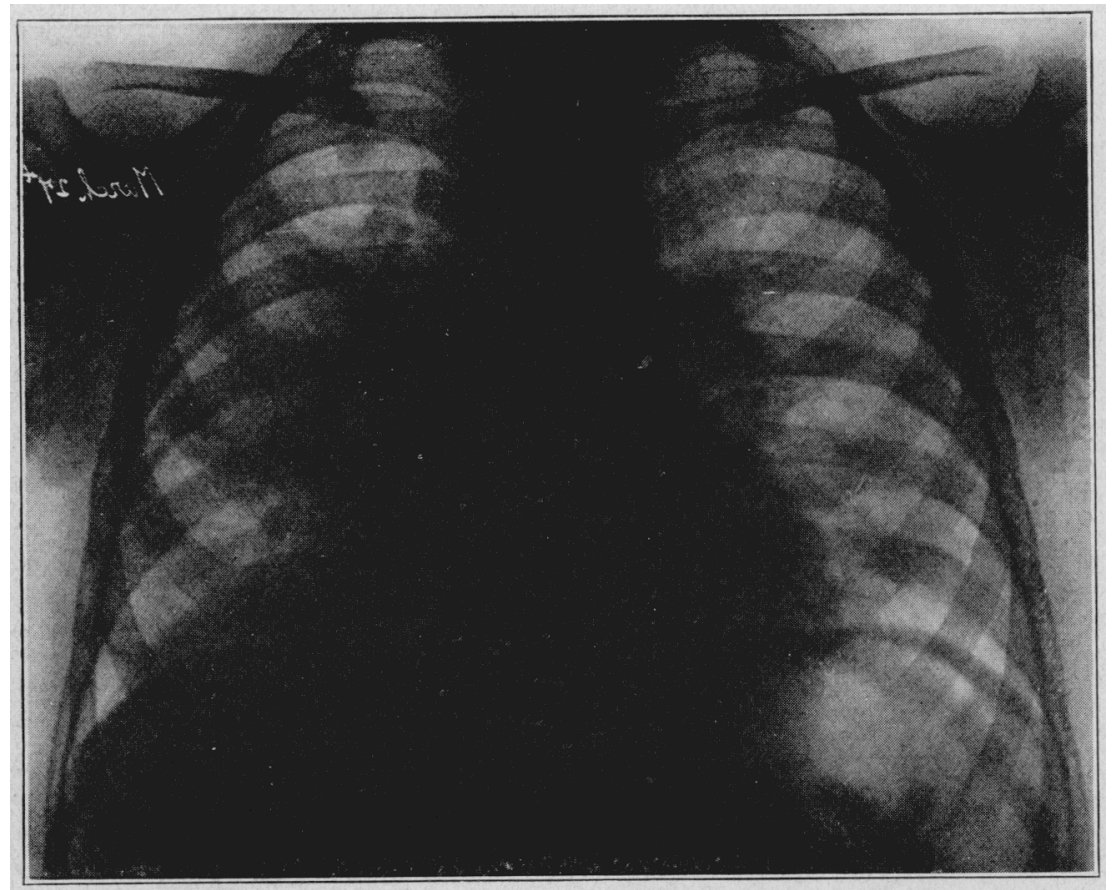

Fis. 3. Case 1. The hilu infiltration is less definitely outlined than in Figure 2. 
Present Illness.-Became ill with a temperature of $102 \mathrm{~F}$, vomited twice at onset; was treated for influenza for two days before I saw her.

Physical Examination.-On examination, I found a fairly well nourished child, not perceptibly prostrated; temperature $103.5 \mathrm{~F}$., fairly rapid pulse; respiration about 30 and acid breath. The skin and glands were negative, as were the mucous membranes; no catarhal symptoms. The rest of the examination was negative, except for a palpable liver and spleen.

Diagnosis.-A diagnosis of acidosis was made, and the child was treated accordingly. The irregular fever, however, continued for over a month, uninfluenced by treatment. The course of the fever is interesting. It would remit several times during the twenty-four hours and was often highest in the morning and after sleep. The child perspired rather freely. During this period the child never vomited again, had no diarrhea, took its food fairly well and slept normally. The child was examined by several consultants and nothing characteristic was found. I had noticed slight dyspnea several times, but paid no particular attention to it.

Laboratory Examinations.-Several blood examinations showed a high leukocytosis, from 24,300 to 31,000 , with from 60 to 65 per cent. polymorphonuclears. Blood and urine cultures were negative.

\begin{tabular}{|c|c|c|c|c|c|}
\hline Date & Leukocytes, & $\begin{array}{l}\text { Polymorpho- } \\
\text { nuclears, } \\
\text { per Cent. }\end{array}$ & $\begin{array}{l}\text { Lympho- } \\
\text { cytes, } \\
\text { per Cent. }\end{array}$ & $\begin{array}{l}\text { Fosino- } \\
\text { phils, } \\
\text { per Cent. }\end{array}$ & $\begin{array}{c}\text { Mononuclears } \\
\text { and } \\
\text { Transitionals, } \\
\text { per Cent. }\end{array}$ \\
\hline $\begin{array}{lr}\text { Nov. } 26 \\
\text { Dec. } \\
\text { Dec. } \\
\text { Dec. } 17 \\
\text { Dec. } 24 \\
\text { Feb. } 4 \\
\text { Mar. } 15 \\
\text { April } 4 \\
\text { Jan. } 29\end{array}$ & $\begin{array}{l}24,600 \\
27,000 \\
34,000 \\
31,000 \\
23,000 \\
26,000 \\
39,600 \\
28,000 \\
29,000\end{array}$ & $\begin{array}{l}60 \\
57 \\
63 \\
61 \\
54 \\
64 \\
71 \\
69 \\
67\end{array}$ & $\begin{array}{l}39 \\
40 \\
35 \\
38 \\
40 \\
30 \\
29 \\
28 \\
33\end{array}$ & $\begin{array}{l}1 \\
3 \\
2 \\
1 \\
2 \\
- \\
1 \\
-\end{array}$ & $\begin{array}{l}- \\
- \\
- \\
4 \\
6 \\
- \\
-\end{array}$ \\
\hline
\end{tabular}

Clinical Course.-At the end of about thirty-two days the temperature came down by lysis and remained about normal for several weeks, when it mounted again. About this time the dyspnea became more marked, especially on exertion. This dyspnea was expiratory and was suggestive of pressure behind the pharynx. A search for retropharyngeal suppuration was negative. Diminished breathing over the right lobe posteriorly and slight impairment of resonance was also noticed at the same time.

In the meantime pus was found in the urine and our attention was called to the possibility of latent pyelitis being responsible for the entire clinical picture. Clearing up of the pyuria was not associated with disappearance of the other symptoms, but the diminished breathing and resonance became somewhat more pronounced and the child was then fluoroscoped and radiographed. The roentgenograms showed a triangular area (Figs. 2, 3, 4, 5, 6 and 7), the true nature of which was not then detected.

The diagnosis (roentgenographic) at that time was multiple abscesses or encysted empyema and operation was advised. Chest puncture, however, failed to locate the pus, and the material obtained was injected into a guinea-pig. A von Pirquet test was made about this time and proved strongly positive. Before the guinea-pig could be killed, tubercle bacilli were found in the sputum after more than twenty examinations were made. Two weeks later the guineapig showed tuberculosis.

We were reluctant to consider this case tuberculous because of the blood count, which persistently showed a high leukocytosis, and 


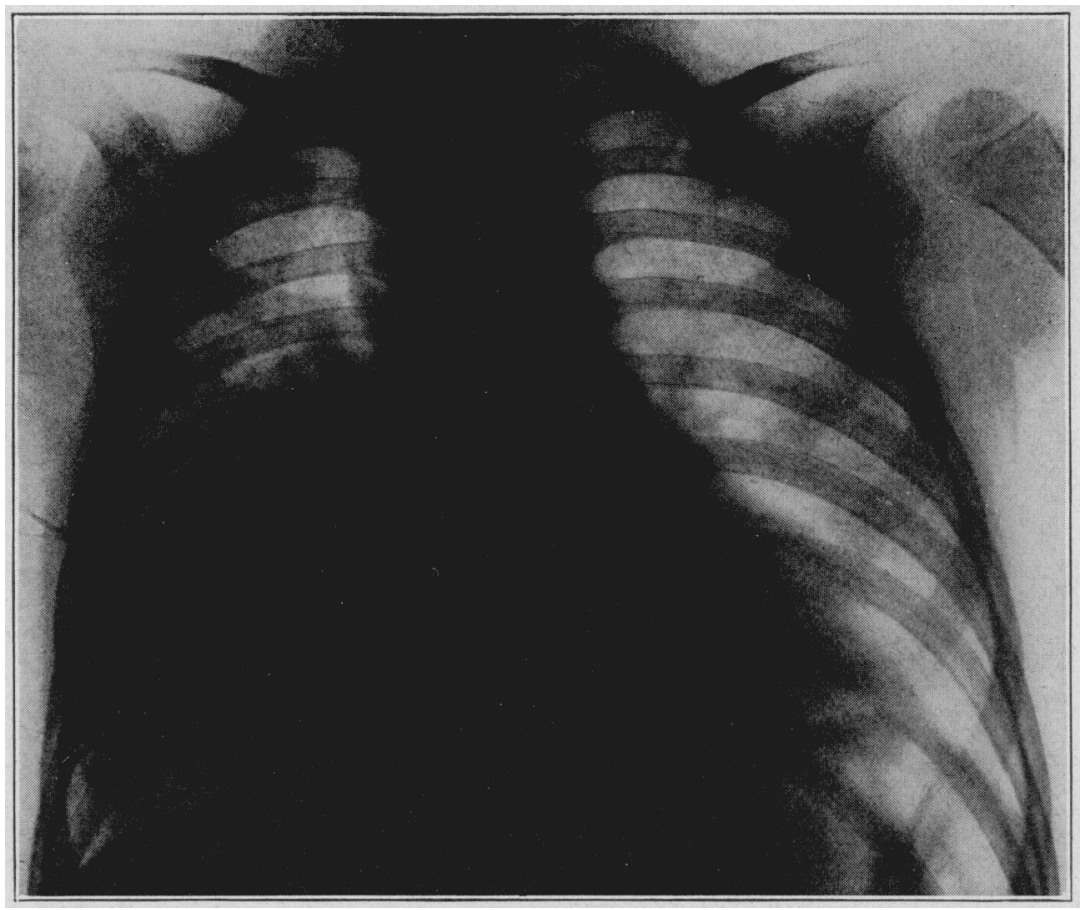

Fis. 4... Gase 1. Sereral weeks later. the puetes apparently wats extending

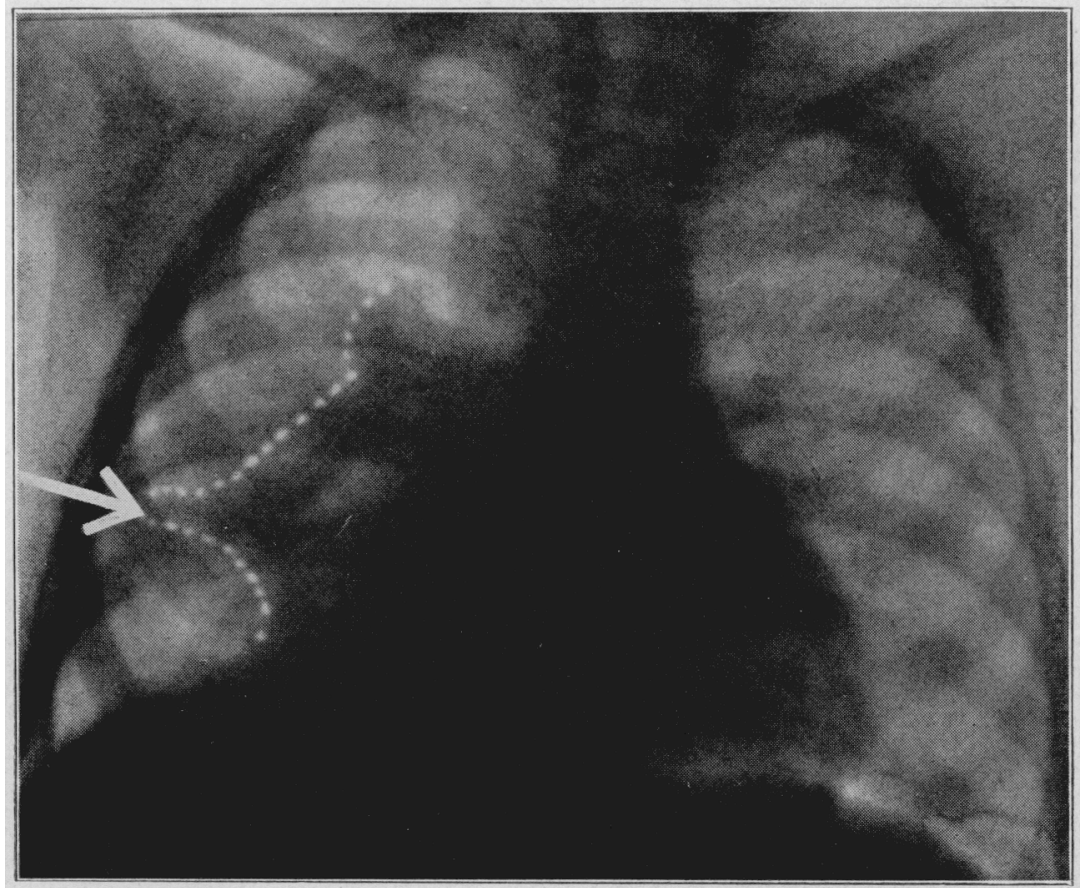

Fig. 5.-Case 1. The process is secul extending along the interlutar fissure. The arrow inclicales the presence of irea air. 


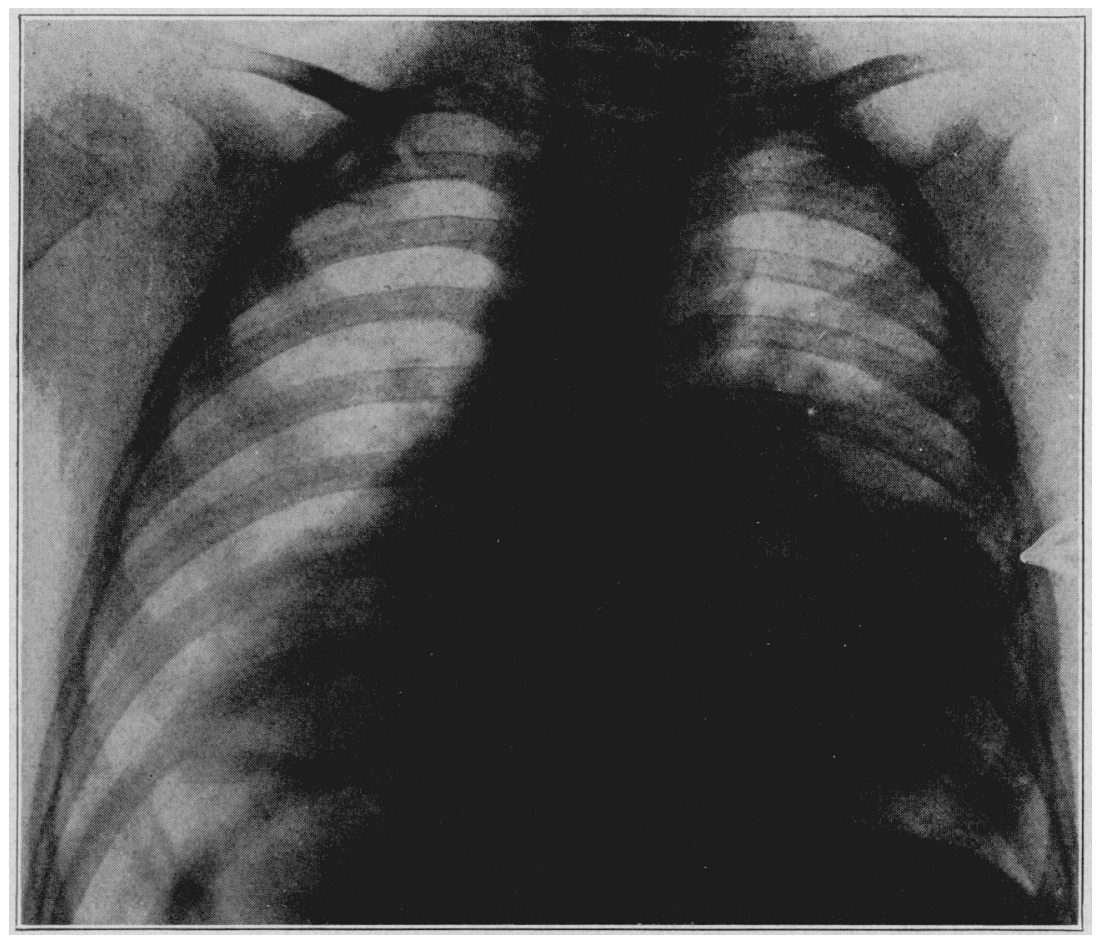

Fin. 6.... Case 1. The process is seen extemling along the interlobar fissure.

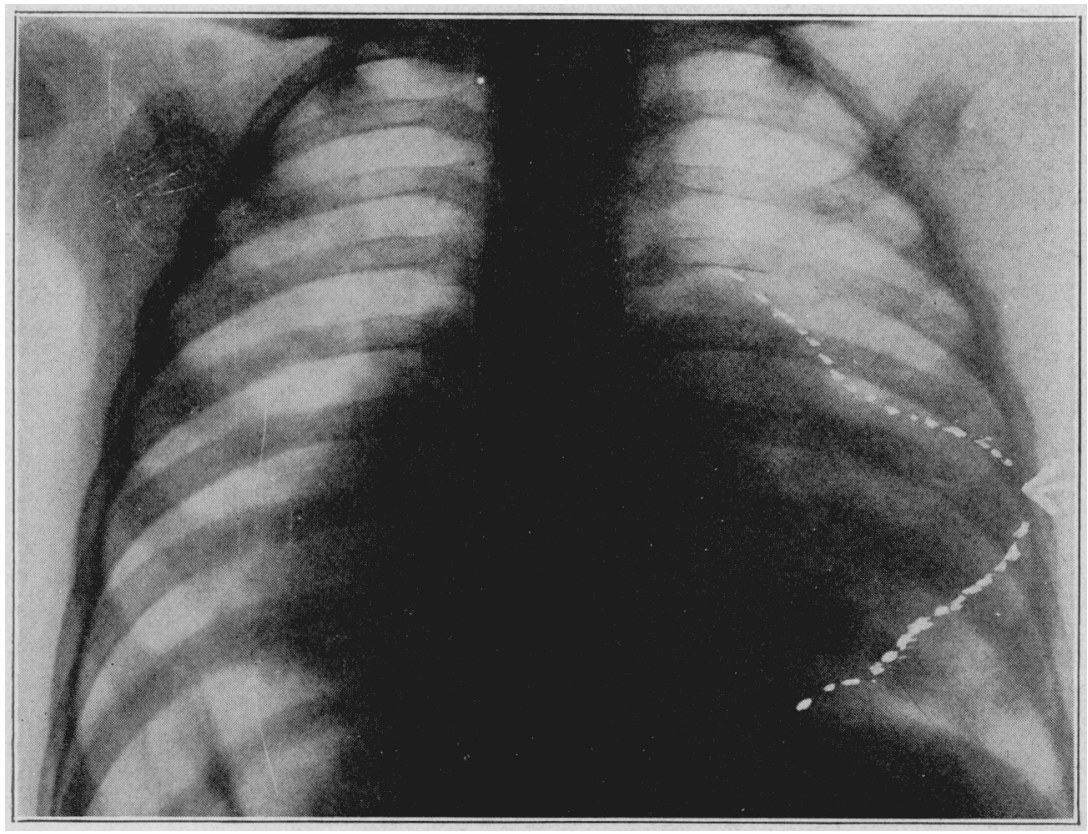

Fig. 7.-Case 1. Niter a short stay of the patient in the country. the shadow is less dense. 
the relative freedom of the upper part of the lung from all evidence of infiltration. The sputum examination and the results of the guinea-pig inoculation definitely established the diagnosis.

After the diagnosis was established, the child was sent to the country and began to improve almost immediately so that now, about a year and a half after the first onset of illness, the child is apparently almost entirely well.

CASE 2.-H. C., male, aged 17 months.

Family History.-One brother died of meningitis (?).

Previous History.-Normal birth, fourth in the family, breast-fed up to $11 \frac{1 / 2}{2}$ months, no other illnesses. Was told he had enlarged tonsils and adenoids.

Present Illness.-Became ill about June, 1919, with fever, which, according to mother's statement, would come and go. The child was seen by several physicians within the first four weeks of its illiess and various diagnoses were made. The family at first did not think that the child's condition was serious, but they became worried after the fever had lasted about a month. While the child had fever almost every day it would still play and would not stay in bed. The mother did not know how high the fever was. When I first saw the patient he had grown perceptibly worse. He had begun to sweat more or less profusely, especially after sleep, and had occasional attacks of hoarseness. No cough was noted previous to this time.

Physical Examination. - Patient was a fairly well nourished child, but slightly prostrated; skin and mucous membranes negative; temperature 103.2 F., pulse 136 , respirations 28 ; head somewhat square-shaped, fontanel open; palpable cervical lymph glands; two very small lymph nodes in right supraclavicular fossa. Chest shows a slight rachitic rosary; moderate dulness over lower lobe posteriorly, except at the very base; relative dulness in right axilla, diminished breathing in axilla, distant bronchovesicular breathing posteriorly, a few fine crepitant râles in the axilla and posteriorly just below the angle of the scapula. The rest of the examination is negative.

Laboratory Examination.-The urine was negative. The sputum, which was obtained by tickling the larynx and catching the coughed-up material on sterile gauze, was negative on three occasions. The blood count was 16,400 leukocytes, with 65 per cent. polymorphonuclears. A chest puncture yielded no fluid and some of the material withdrawn, which consisted of blood stained detritus, was injected into a guinea-pig. Some of this material showed tubercle bacilli by direct spread examination.

The roentgenograms were almost identical with those of Case 1 , i. e., the lesion was on the right side, triangular in outline, irregular in density, with a tendency to follow interlobar fissure (Figs. 8, 9, 10 and 11). The roentgenologist made a diagnosis of interstitial pneumonia, probably caused by a foreign body and advised a bronchoscopic examination which, of course, was not done. Subsequently, tubercle bacilli were also found in the sputum. The leukocyte count remained between 16,000 and 21,000 .

\section{SUMMARY}

1. Extensive tuberculous lesions about the hilus may occur in infants and young children which pursue a rather chronic course.

2. Recovery probably takes place in the majority of these cases even in children under 2 years of age. 


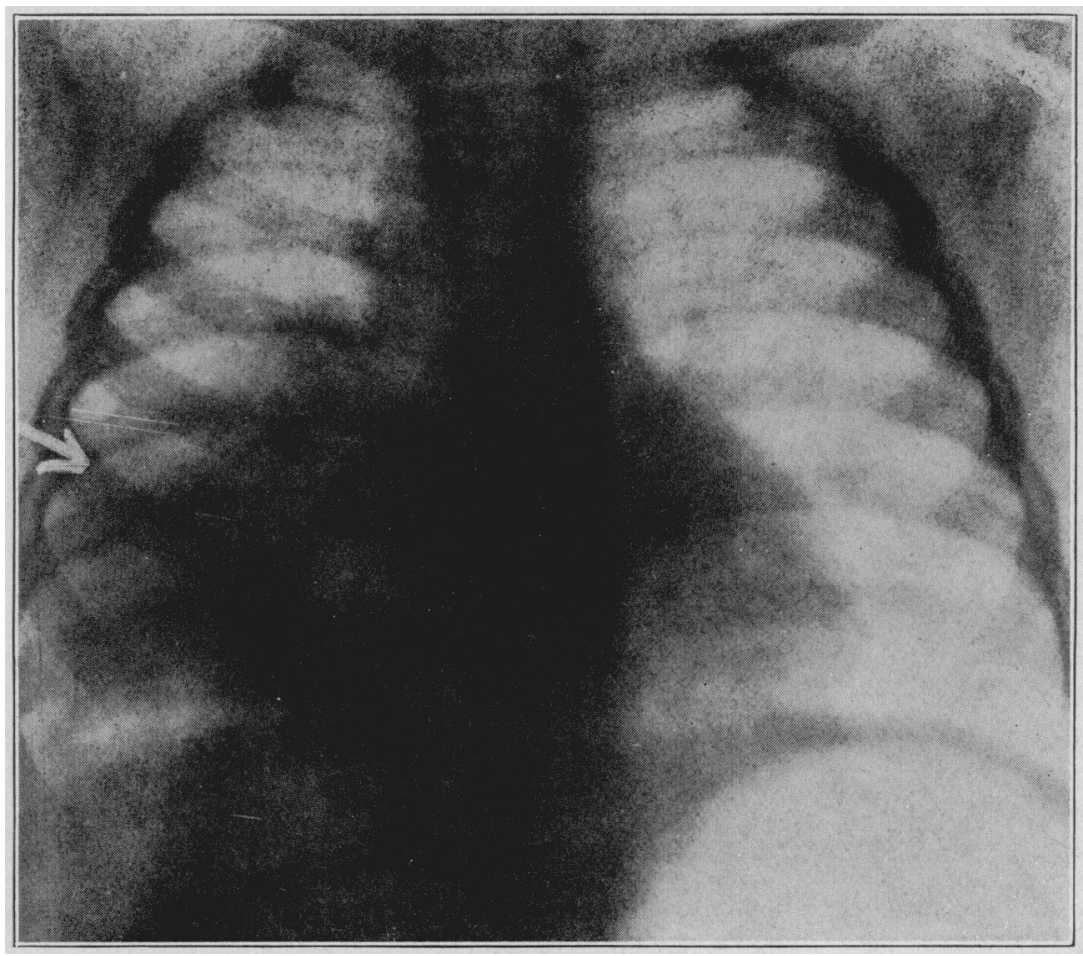

Figure \&

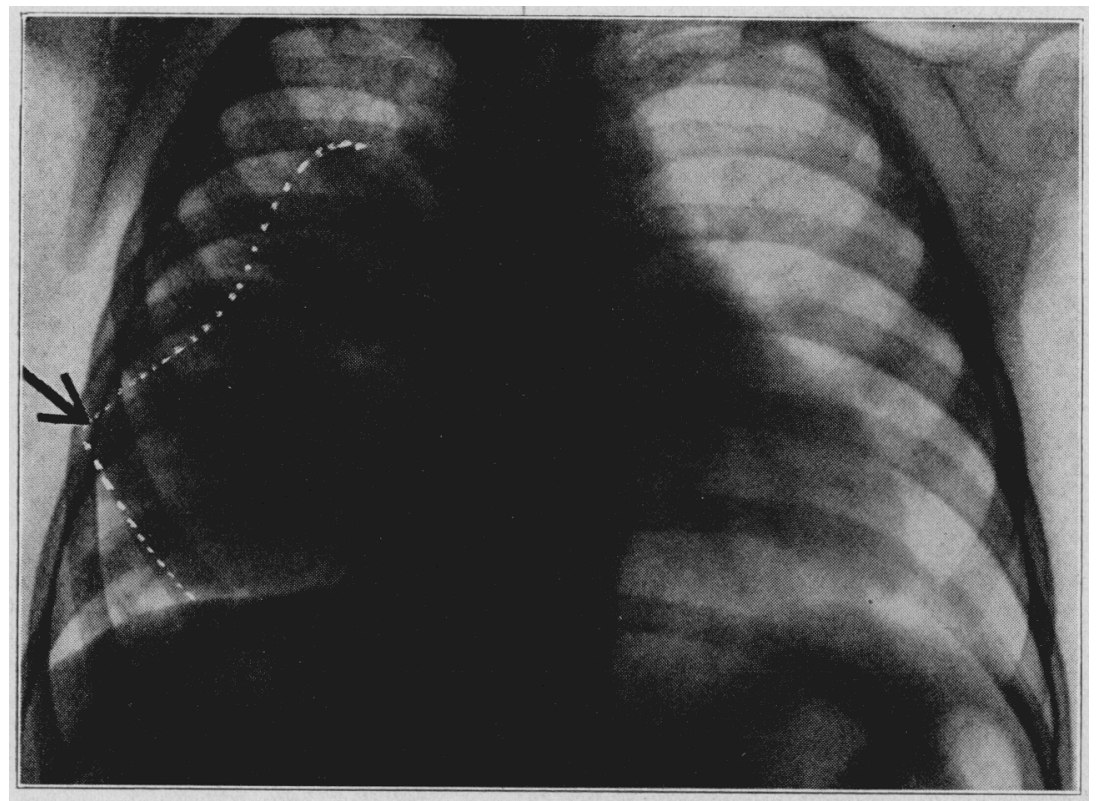

Figure 9

Figs. 8 and 9.-Case 2. Characteristic triangular ontline, base toward hilus. 


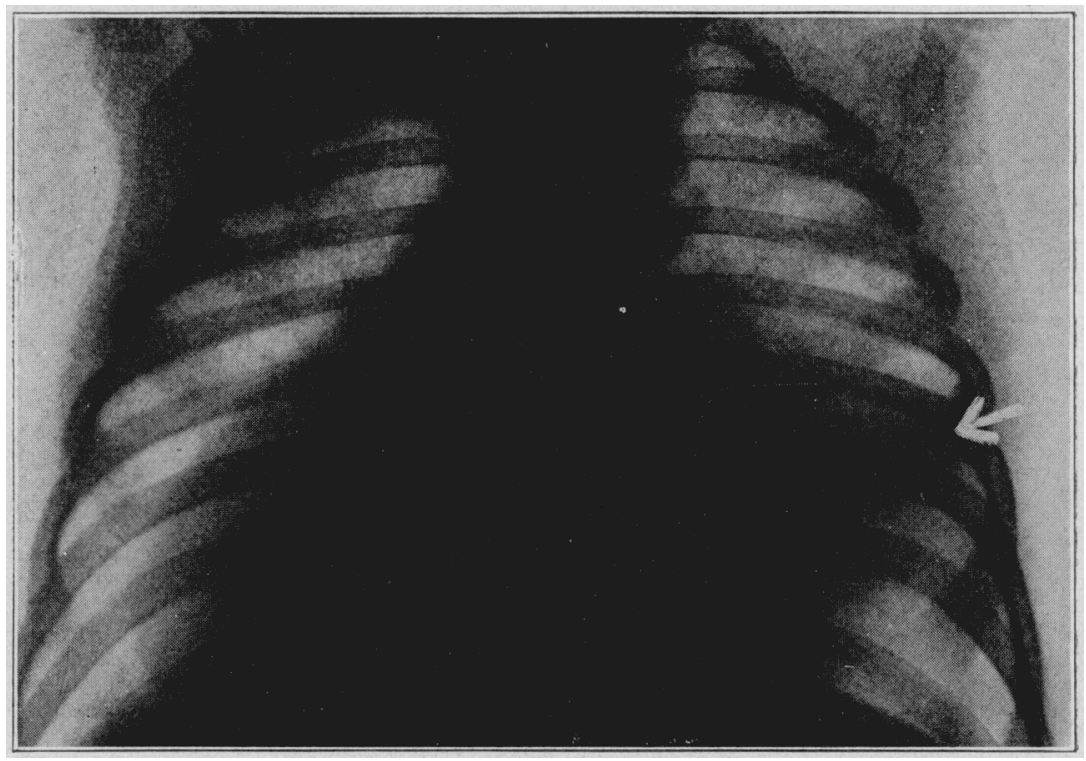

Figure 10

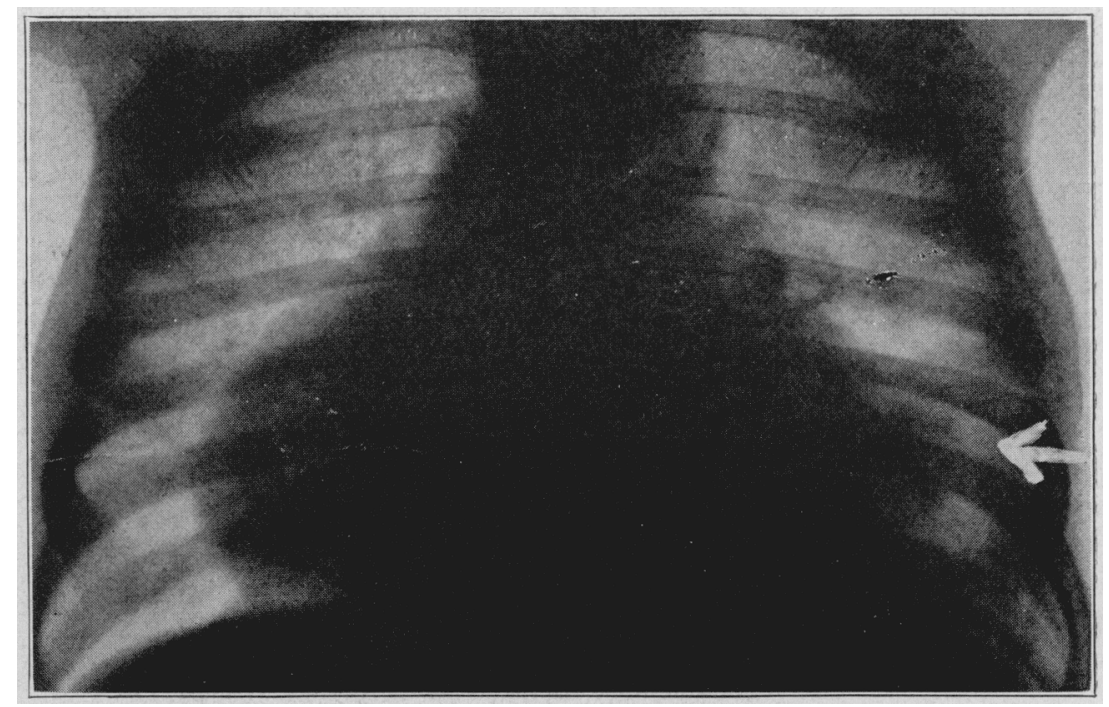

Figure 11

Figs. 10 and 11.-Xore extensive involvement with irregulat density at a time when there hegan to be clinical improrement. 
3 . The onset in this type of pulmonary tuberculosis is more or less gradual and there may be no lung signs until after the disease has lasted for some time.

4. Irregular fever, sweating, expiratory obstruction, diminished breathing, with impaired resonance, a positive von Pirquet and a characteristic roentgen-ray picture, are among the earlier manifestations.

5. Enlargement of the supraclavicular lymph nodes, positive results from guinea-pig inoculation of material from lung puncture or of sputum, and the presence of tubercle bacilli in the sputum may be found later in the course of the disease.

6. Given an infant or child with prolonged irregular fever and sweating, showing a positive von Pirquet, this form of tuberculosis should be suspected and its further early manifestations sought for. 